\title{
$A$ ARP Alabama
}

\section{VITAL \\ VOICES}

Issues That Impact Alabama Adults Age 45 and Older, October 2021

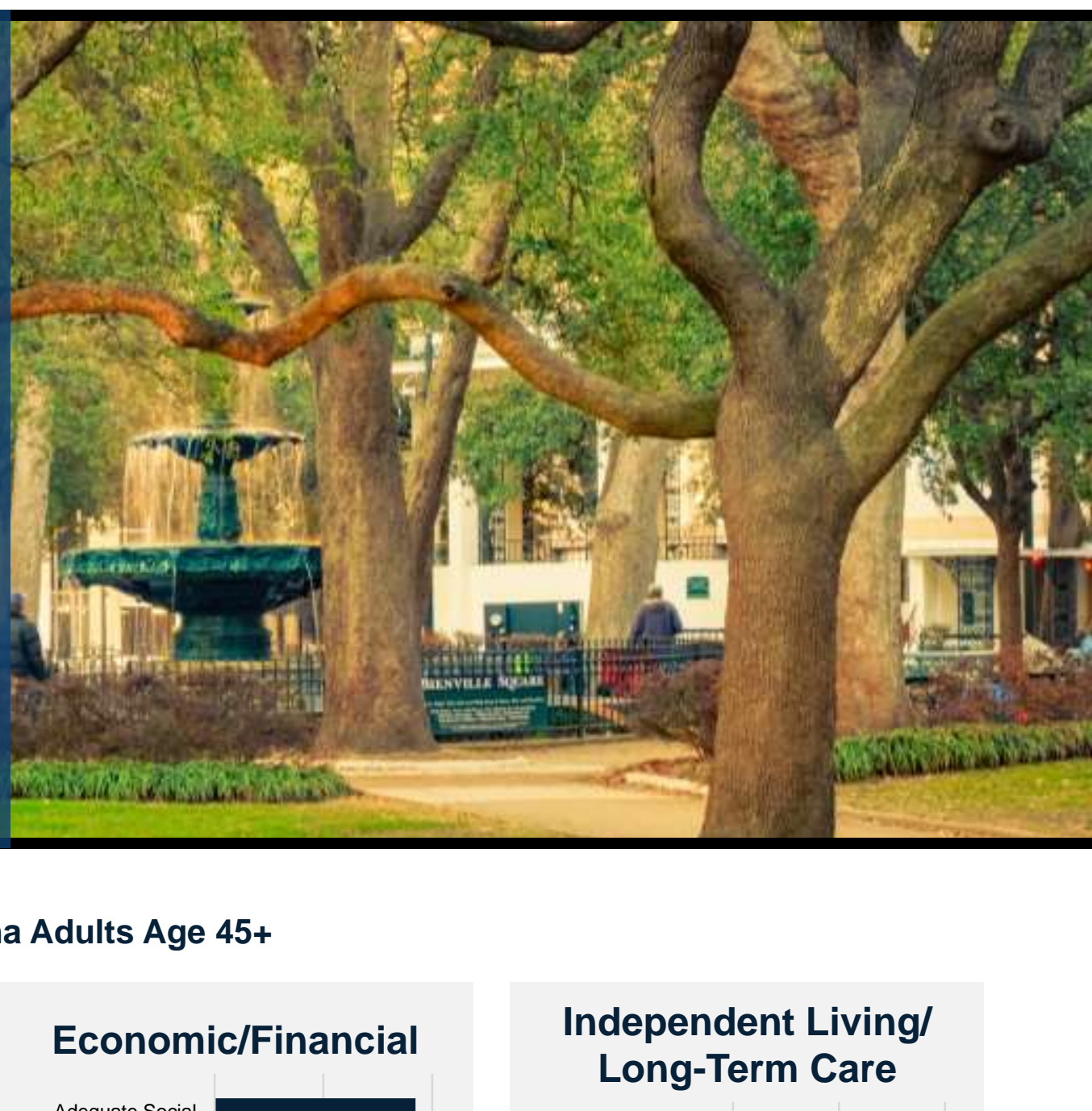

Issues of Importance to Alabama Adults Age 45+

\section{Health Care}

Adequate health insurance coverage

Staying mentally
sharp

Staying physically healthy
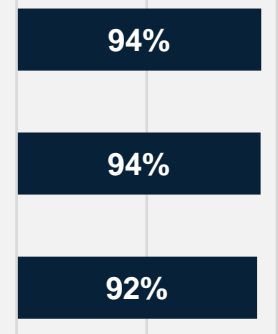

$92 \%$
Medicare benefits available in the future

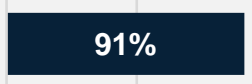
Paying for health
care expenses

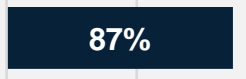

Paying for prescription drugs

\section{Economic/Financial}

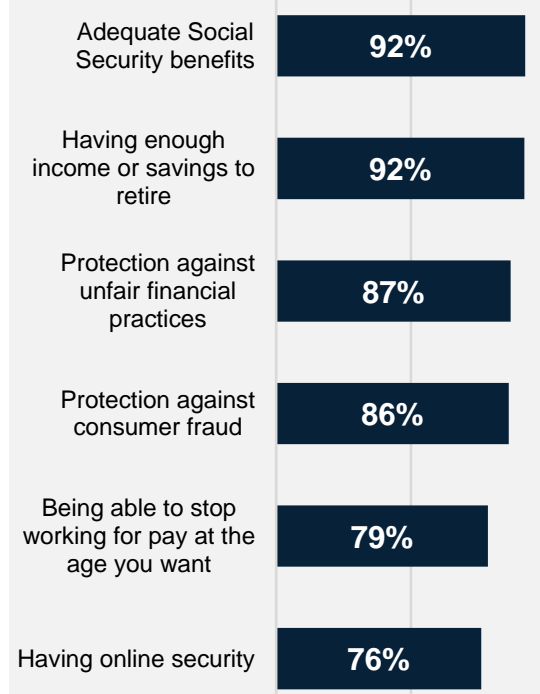

$0 \% \quad 50 \% \quad 100 \%$

\section{Independent Living/ Long-Term Care}

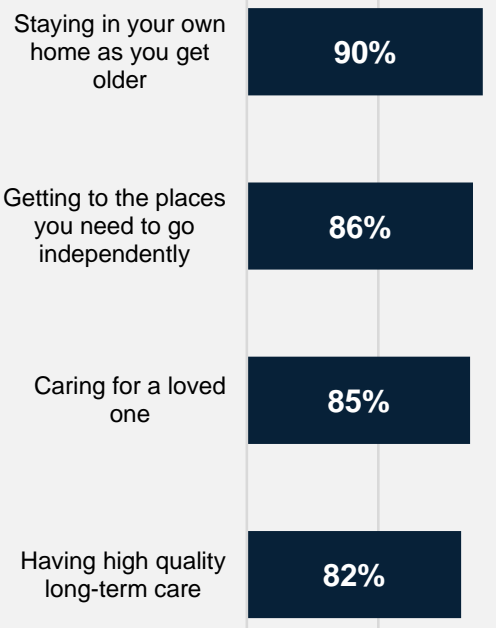

$0 \% \quad 50 \% \quad 100 \%$

"For the following list of issues, please indicate how important each is to you personally." $\%$ "extremely important" or "very important" 


\section{Vital Voices: Issues That Impact Alabama Adults Age 45 and Older, October 2021}

Interviews were conducted with 734 residents of Alabama by landline (45\%), cell phone (25\%), and online (30\%) between September 16, 2021 and October 3, 2021.

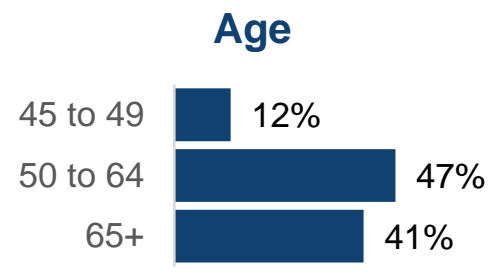

Employment

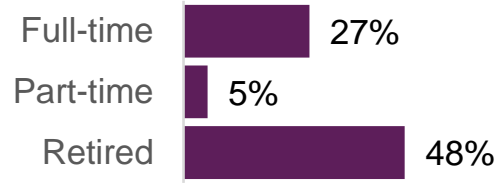

\section{Gender}

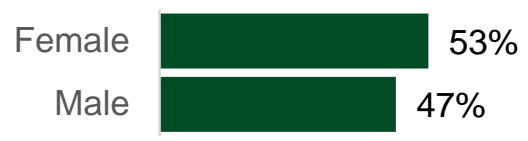

Race/Ethnicity

White/ Caucasian

Black/ African American

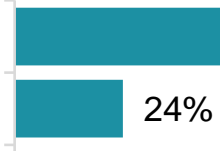

Other $4 \%$

\section{Political Views}

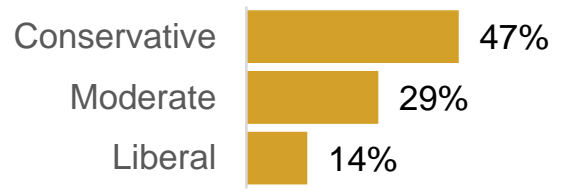

\section{Education}

Some college or less

4-year college degree

Post-graduate study or degree

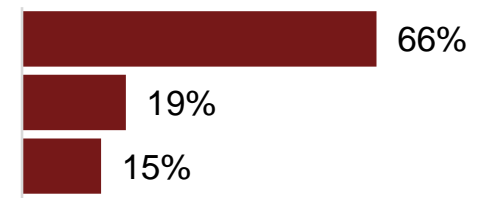

\section{Marital Status}

Married/ living with partner

Divorced/ separated

Widowed

Never married

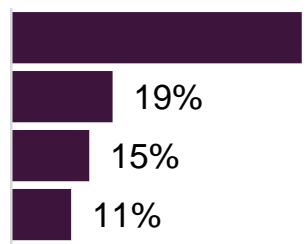

$55 \%$

\section{Annual Household Income}

Less than $\$ 50,000$

$\$ 50,000$ to less than $\$ 100,000$

$\$ 100,000+$

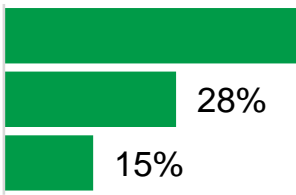
$48 \%$

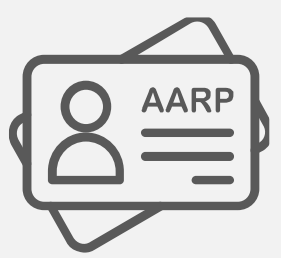

$26 \%$

AARP Member

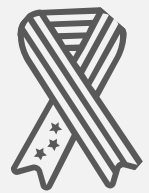

$22 \%$

Veteran 